
Integral Fast Reactor Integral Fast Reactor Integral Fast Reactor Integral Fast Reactor Integral Fast Reactor Integral Fast Reactor Integral Fast Reactor

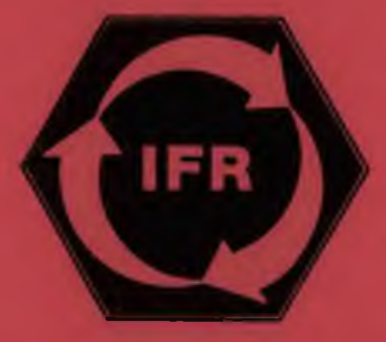
NOV 051985 Integral Fast Reactor Integral Fast Reactor Integral Fast Reactor Integral Fast Reactor Integral Fast Reactor Integral Fast Reactor Integral Fast Reactor Integral Fast Reactor Integral Fast Reactor Integral Fast Reactor Integral Fast Reactor Integral Fast Reactor Integral Fast Reactor Integral Fast Reactor Integral Fast Reactor

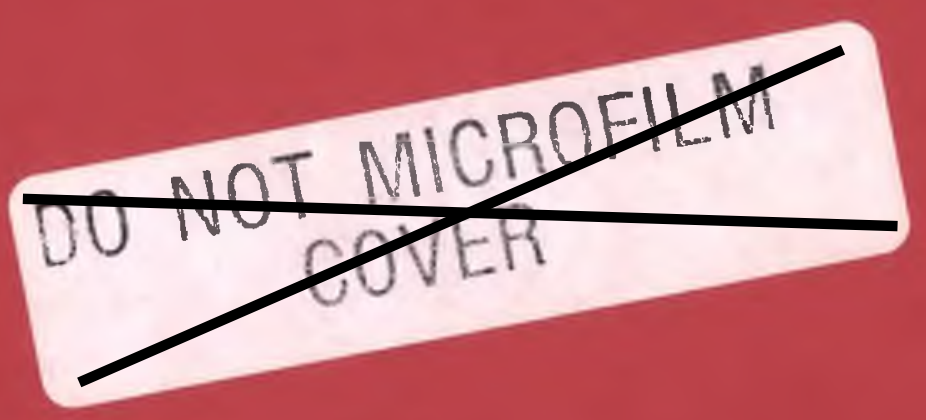
Integral Fast Reactor Integral Fast Reactor

\title{
Quasi-Static Transient Analysis
}

by R. H. Sevy

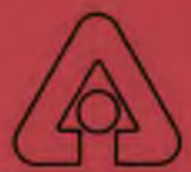

Argonne National Laboratory, Argonne, Illinois 60439

operated by The University of Chicago

for the United States Department of Energy under Contract W-31-109-Eng-38

IFR Tochnteal Memorandum

Results reported in the IFR-TM series of

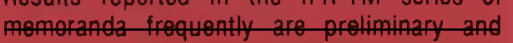
subioc to rvision. Consently thoy should

not bo quated of roferenced without the

author's pormission.

\section{NO ACCESS RESTRICTIONS}

This document is not considered OUO-Applied Technology. It was reviewed for Export Controlled Information and found to be suitable for unlimited access and reproduction.

This label reflects Applied Technology instructions issued April 13, 2006, by the the Department of Energy Office of Nuclear Energy. Additional guidance has also been provided by DOE in 2016 and 2018 memos, as well as from NNSA.

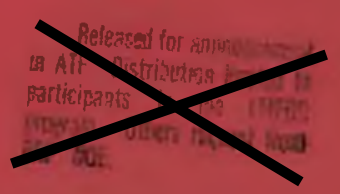

Poul Petlen Paul Betten, ANL 
Argonne National Laboratory, with facilities in the states of Illinois and Idaho, is owned by the United States government, and operated by The University of Chicago under the provisions of a contract with the Department of Energy.

\section{DISCLAIMER}

This report was prepared as an account of work sponsored by an agency of the United States Government. Neither the United States Government nor any agency thereof, nor any of their employees, makes any warranty, express or implied, or assumes any legal liability or responsibility for the accuracy, completeness, or usefulness of any information, apparatus, product, or process disclosed, or represents that its use would not infringe privately owned rights. Reference herein to any specific commercial product, process, or service by trade name, trademark, manufacturer, or otherwise, does not necessarily constitute or imply its endorsement, recommendation, or favoring by the United States Government or any agency thereof. The views and opinions of authors expressed herein do not necessarily state or reflect those of the United States Government or any agency thereof.

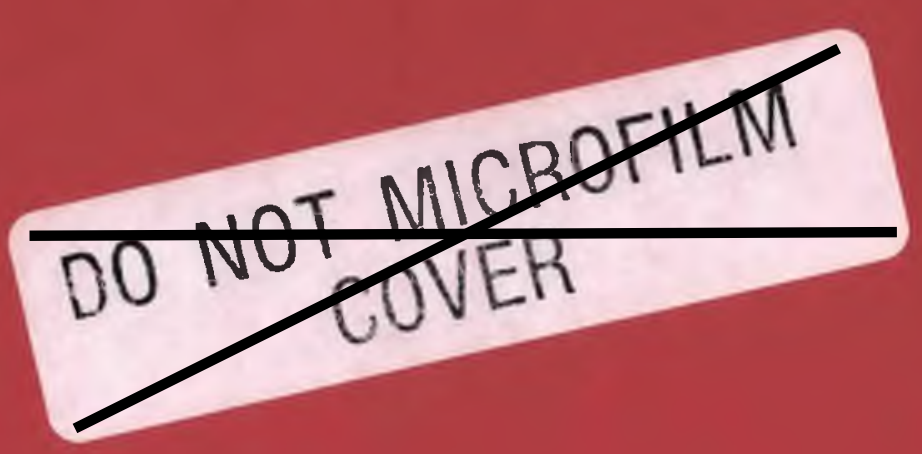




\section{DISCLAIMER}

This report was prepared as an account of work sponsored by an agency of the United States Government. Neither the United States Government nor any agency Thereof, nor any of their employees, makes any warranty, express or implied, or assumes any legal liability or responsibility for the accuracy, completeness, or usefulness of any information, apparatus, product, or process disclosed, or represents that its use would not infringe privately owned rights. Reference herein to any specific commercial product, process, or service by trade name, trademark, manufacturer, or otherwise does not necessarily constitute or imply its endorsement, recommendation, or favoring by the United States Government or any agency thereof. The views and opinions of authors expressed herein do not necessarily state or reflect those of the United States Government or any agency thereof. 


\section{DISCLAIMER}

Portions of this document may be illegible in electronic image products. Images are produced from the best available original document. 
This-report contains information of a preliminary nature and was prepared primarily for internal use at the origint in It is subject to revision of corrotion and therefore does not represent a final report. It is passed to the recipient in confidence and should not be abstracted or further disclosed without the approval of the originating installation or USDOE Offiee of Scientific and Technical Information, Oak Ridge, TN 37830.

QUASI-STATIC TRANSIENT ANALYSIS

by

R. H. Sevy

Reactor Analysis and Safety Division

Argonne National Laboratory

9700 South Cass Avenue

Argonne, Illinois 60439

APPUEO TECHAOLOCY

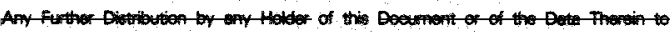

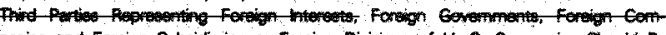

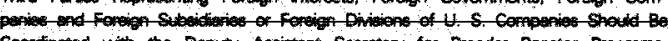

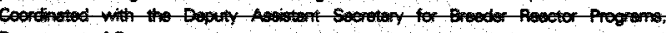
Energr.

IFR TECHNICAL MEMORANDUM NO. 26
ANL-IFR--26

TI86 025243 



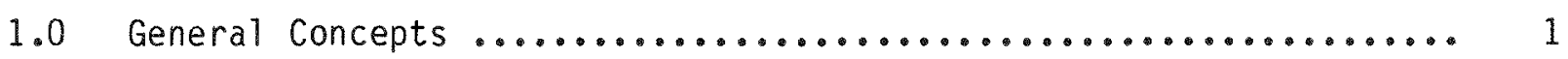

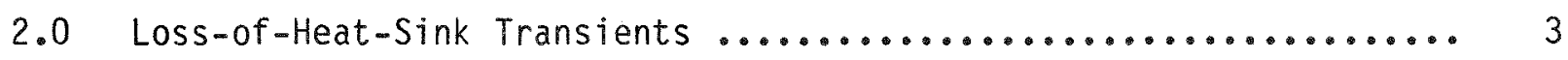

3.0 Loss-of-flow Transients $\ldots \ldots \ldots \ldots \ldots \ldots \ldots \ldots \ldots \ldots \ldots \ldots \ldots . \ldots \ldots$

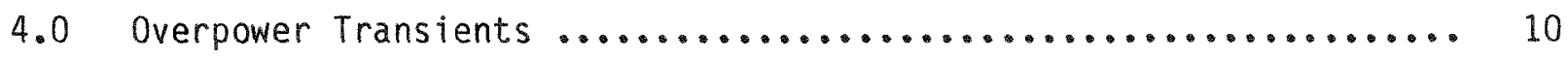

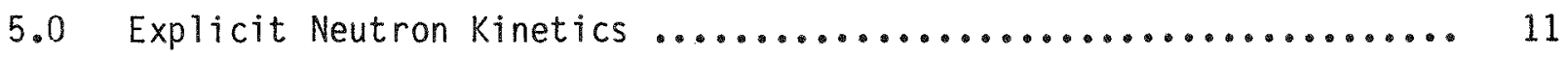

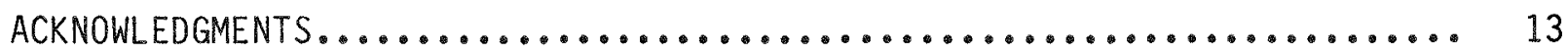

\section{APPENDICES}

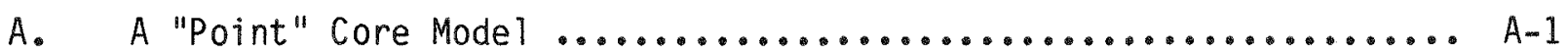

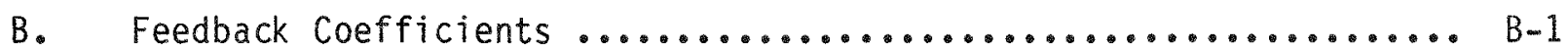

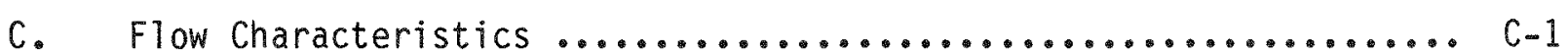

D. Influence of Inlet Temperature Deviations Upon Outlet 


\section{LIST OF FIGURES}

Page

1. Loss-of-Heat-Sink: Power vs. Time ..................... 6

2. Loss-of-Heat-Sink: Coolant Inlet Temperature vs. Time ......... 7

3. Power Deviation from Equilibrium $\ldots \ldots \ldots \ldots \ldots \ldots \ldots \ldots \ldots \ldots$

LIST OF TABLES

Page

1. Feedback Coefficients ............................... 5 


\section{QUASI-STATIC TRANSIENT ANALYSIS}

by

R. H. Sevy

\section{ABSTRACT}

A simple method for calculating reactor response to loss-ofheat-sink, loss-of-flow and overpower transients is developed. The method is applicable to a class of "slow" transients in which the characteristic times of transient forcing functions are large compared to all thermal time constants and compared to the àverage delayed-neutron precursor half-life. 
1.0 General Concepts

A broad class of reactor transients may be characterized as: (1) slow -. in the sense that the spatial distributions of temperatures at all times are close to the steady-state distributions corresponding to the instantaneous power and flow and the delayed neutron precursor concentrations are close to those corresponding to the instantaneous power, and (2) separable -- in the sense that point neutron kinetics and point thermal kinetics are good approximations. Conditions defining the limits of these slow, separable transients are: (1) the phenomenon driving the transient must proceed on a time scale slow compared to the longest thermal time constant in the system and compared to delayed-neutron precursor half-lifes (one-group average $\sim 10 \mathrm{~s}, \mathrm{e.g} ., \mathrm{\text {) }}$; (2) transient perturbations are sufficiently small that direct and adjoint flux shapes are essentially unperturbed; and (3) the temperature distributions either in fact are separable or may reasonably be so approximated.

Examination of specific situations for applicability of the above conditions is a reasonably straightforward matter. Characteristic times for all processes can be estimated and compared. Point neutron kinetics should be adequate for all transients in which reactivity feedback is generated solely by small expansions or contractions of reactor materials and by Doppler broadening. In slow overpower and slow loss-of-heat-sink transients, the temperature distributions are in fact separable -- in slow loss-of-flow transients they are not; however, replacement of certain spatial averages of products by products of averages can be shown to yield a useful separable approximation (Appendix A).

Those transients that meet these conditions of slowness and separability then may be characterized by a single equation that yields some quick insight into the main character of the transient response to any prescribed forcing function.

$$
A[1-P(t)]-B[P(t) / F(t)-1]-\alpha_{i} \delta T_{i}(t)+R t=0
$$

Equation (1) states that net reactivity is zero at all times. It can be derived by using steady-state equations for coolant and fuel temperatures as functions of power and flow to eliminate those temperatures from the 
equation -- which fundamentally is a summation of products of temperature coefficients and temperature deviations. $P(t)$ is relative power as a function of time, $F(t)$ is relative flow, $A, B$, and $\alpha_{i}$ are feedback coefficients defined explicitly in Appendix $B$. $R$ is a reactivity insertion rate. In the quasistatic approximation, all feedback coefficients -- six different feedback mechanisms are included in the subsequent analysis -- may be combined into just these three coefficients. A measures changes in fuel rod radial temperature gradients; $B$ measures changes in coolant temperature gradients through the channels; and $\alpha_{j}$ measures changes in inlet temperature, $\delta T_{j}$. As may be seen by differentiating the equation, $-(A+B)$ is the power coefficient, $B$ is the flow coefficient and $-\alpha_{i}$ the inlet temperature coefficient, each evaluated at normal full power conditions.

$\delta T_{j}(t)$ can be eliminated by expressing it in terms of power and flow as

$$
C_{T} \delta T_{j}(t)=\int_{0}^{t} d t^{\prime}\left[P\left(t^{\prime}\right)-P_{r}\right]-C_{0} \Delta T_{C}[P(t) / F(t)-1]
$$

where $C_{T}$ is the total primary system heat capacity, $C_{0}$ the outlet plenum heat capacity, $\Delta T_{C}$ the normal steady-state temperature increase across the coolant channels, and $P_{r}$ is a time-independent heat rejection rate. The equation can be derived by requiring that all energy in the primary system be stored in steady-state distributions corresponding to the instantaneous power and flow.

Equations (1) and (2) may be combined to get

$$
A[1-P(t)]-B^{\prime}[P(t) / F(t)-1]-\frac{\alpha_{i}}{C_{T}} \int_{0}^{t} d t^{\prime}\left[P\left(t^{\prime}\right)-P_{r}\right]+R t=0
$$

where $B^{\prime} \equiv B-\frac{C_{0}}{C_{T}} \Delta T_{C} \alpha_{i}$.

Solutions of this equation for $P(t)$ describe transient response completely. Other quantities of interest, variations in inlet and outlet temperature, e.g., may be computed from their definitions in terms of power. 
For many situations, closed form solutions are straight-forward: with constant inlet temperature, the equation is algebraic; with variable inlet temperature it is a first-order differential equation; the condition of quasistatic neutron kinetics can be relaxed resulting in a nonlinear equation that can be linearized to a good approximation that again results in a first-order differential equation. Each of these matters is illustrated below.

We restrict our attention to systems that have positive flow coefficients and negative power and inlet temperature coefficients. This implies that $A$, $B$, and $\alpha_{i}$ all are positive numbers. These conditions are sufficient to assure bounded solutions for power under all circumstances. The conditions typically are met in a broad variety of liquid metal fast reactor designs. Under these conditions, power eventually will start to decline in any type of transient -in loss-of-flow and loss-of-heat=sink a monotonic power reutuction occurs -- in overpower transients, power increases until reactivity insertion is complete, then declines as temperatures continue to increase. Equation (3) holds throughout these transients until the total power is reduced to decay power levels, i.e., so long as fission power is non-zero. Subsequent to that time, power of course follows the decay power function -- reactivity departs from the near zero value of Eq. (3) to increasingly negative values so long as overheating continues. In many circumstances, decay power is effected negligibly by the transient power history and therefore can be determined by the pretransient history. The conditions at transition to decay power then may be determined straightforwardly.

\subsection{Loss-of-Heat-Sink Transients}

We define loss-of-heat-sink transients (LOHS) as any fault or combination of faults in main heat transport or power conversion systems (outside the primary system) which perturbs normal heat rejection capacity -- coupled with failure to scram. In such circumstances primary flow is maintained $[F(t)=1]$ and there is no impressed reactivity $(R=0)$. Equation ( 1 ) then reduces to

$$
[A+B][P(t)-1]+\alpha_{i} \delta T_{i}(t)=0 .
$$

The increase in inlet temperature required to drive power to near zero such that decay heat systems can stabilize system temperatures follows directly from this equation. 


$$
\delta \hat{T}_{i}=\frac{A+B}{\alpha_{i}}
$$

By setting $\delta T_{i} \leqslant \delta T_{i \ell}$, a temperature limit ordinarily set by considerations of high-temperature creep in core support structures, we get

$$
\frac{A+B}{\alpha_{i}} \leqslant \delta T_{i \ell}
$$

$A+B$ is the absolute value of the power coefficient. Equation (4) therefore may be written as

$$
\frac{|P \cdot C .|}{|\mathrm{I} \cdot \mathrm{C} \cdot|} \leqslant \delta T_{i \ell}
$$

where $\left|I_{0} C_{0}\right| \equiv \alpha_{i} \equiv$ absolute value of the inlet temperature coefficient. Equation (4-a') then is a criterion upon the feedback coefficients necessary to avoid damage in a LOHS transient. This creep criterion is more demanding than nonboiling or cladding failure criteria which therefore automatically are met.

In LOHS Eq. (3) reduces to

$$
\left[A+B^{\prime}\right][P(t)-1]+\frac{\alpha_{i}}{C_{T}} \int_{0}^{t} d t^{\prime}\left[P\left(t^{\prime}\right)-P_{r}\right]=0
$$

which may be differentiated with respect to time to get

$$
\left(A+B^{\prime}\right) \frac{d}{d t} P(t)+\frac{\alpha}{C_{i}}\left[P(t)-P_{r}\right]=0
$$

then integrated to yield

$$
P(t)-P_{r}=\left(1-P_{r}\right) e^{-t / \tau}
$$

where $\tau \equiv\left(A+B^{\prime}\right) C_{T} / \alpha_{i}$ is a characteristic time for LOHS transients. 
Equation (5) is a complete solution for a LOHS transient. Other quantities of interest, variations in inlet and outlet coolant temperatures, e.g., may be computed from their definitions in terms of power. $\delta T_{j}(t)$ is defined in $E q .(2) . \delta T_{0}(t)$ is given by

$$
\delta T_{0}(t)=\delta T_{i}(t)+\Delta T_{C}[P(t) / F(t)-1]
$$

Results for typical large $\left(10^{3}\right.$ MWe) oxide and metal cores are illustrated in Figs. 1 and 2. Feedback coefficients, heat capacity and other data used are listed in Table 1. As a consequence of an imbalance between heat generation and rejection, primary coolant temperatures rise. Increasing inlet temperature reduces power and coolant temperature rise across the core and thereby drives the system toward an isothermal, high-temperature, low-power condition. The principal question then is whether power can be reduced such that decay heat removal systems can arrest the temperature rise at temperatures low enough to prevent damage. As illustrated in the figures, we have used a creep temperature 1 imit of $700^{\circ} \mathrm{C}$ (normal inlet temperature of $350^{\circ} \mathrm{C}$ which leads to an allowable increase of an additional $350^{\circ} \mathrm{C}$ ).

TABLE 1. Feedback Coefficients

\begin{tabular}{|c|c|c|}
\hline & Oxide $\left(10^{3}\right.$ MWe) & Metal $\left(10^{3} \mathrm{MWe}\right)$ \\
\hline$A(\phi)$ & 170 & 15 \\
\hline$B(\phi)$ & 40 & 30 \\
\hline$\alpha_{i}\left(\phi /{ }^{\circ} \mathrm{C}\right.$ & 0.40 & 0.30 \\
\hline$C_{T}\left(f p s^{*} /{ }^{\circ} \mathrm{C}\right)$ & 1.0 & 1.0 \\
\hline
\end{tabular}

*fps $\equiv$ full power seconds.

As can be seen from the figures normally-designed, high-performance metallic fueled systems can survive any combination of balance of plant faults without scram, without system damage, whereas analogous oxide fueled systems require restoration of a large fraction of the normal heat rejection systems within a few minutes to avoid damage. 


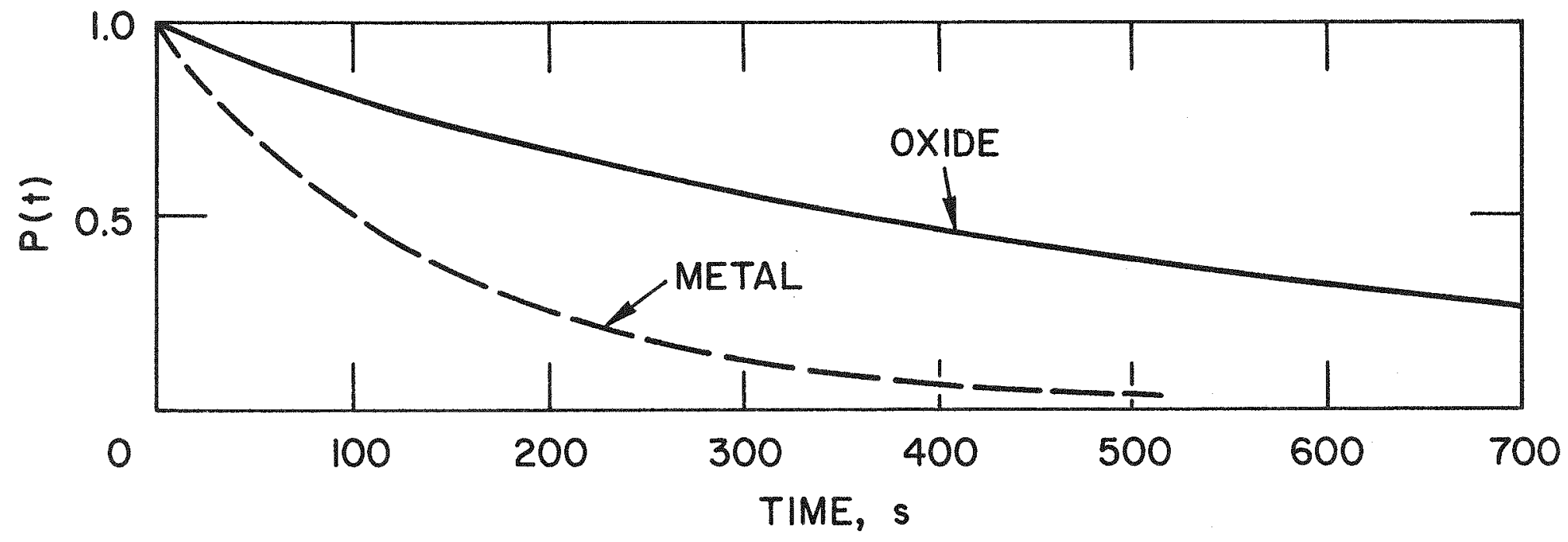

Figure 1. Loss-of-Heat-Sink: Power vs. Time 


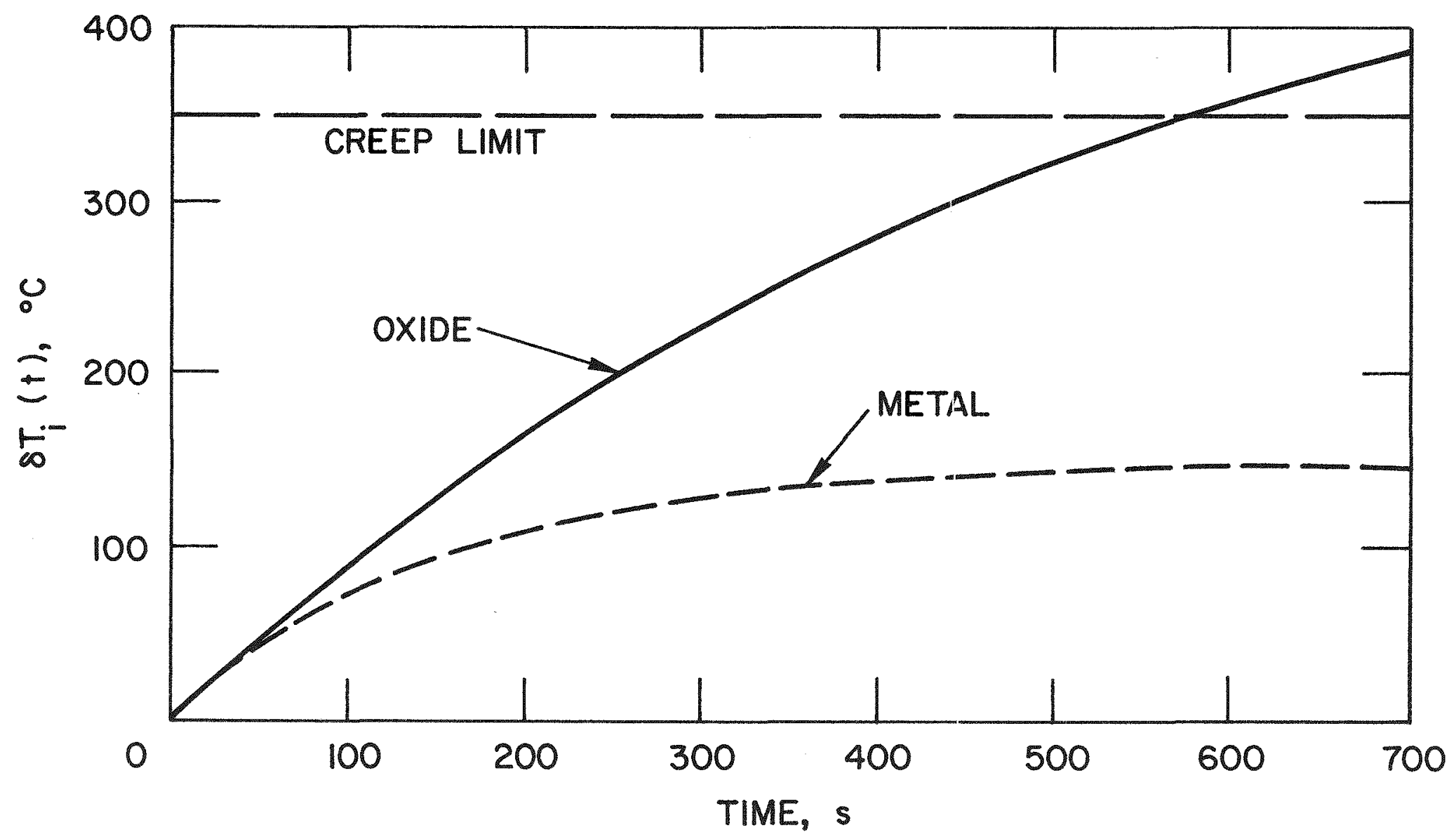

Figure 2. Loss-of-Heat-Sink: Coolant Inlet Temperature vs. Time 


\subsection{Loss-of-flow Transients}

We define loss-of-flow transients (LOF) as primary coolant flow decay to natural circulation levels, plus complete loss of normal heat sink, plus failure to scram. Such a combination could occur as a result of loss of offsite power plus failure to scram, e.g.

For LOF transients, Eq. (1) reduces to

$$
A[1-P(t)]-B\left[\frac{P(t)}{F(t)}-1\right]-\alpha_{i} \delta T_{i}(t)=0
$$

Two useful limits may be deduced directly from the equation. During flow rundown to stable natural convection flow, variations in inlet temperature are small and may be neglected -- a consequence of a large primary system heat capacity. (The development in Appendix $D$ shows further that deviations in outlet temperature in general are highly insensitive to deviations in inlet temperature.) The equation then reduces to

$$
\begin{aligned}
& A[1-P(t)]-B\left[\frac{P(t)}{F(t)}-1\right]=0 \\
& \text { or } P(t)=\frac{1+A / B}{1 / F(t)+A / B}
\end{aligned}
$$$$
\text { and } P(t) / F(t)=\frac{1+A / B}{1+A / B F(t)} \text {. }
$$

The limit of Eq. (1-b') as flow (and power) approach zero yields a maximum possible value of power-to-flow ratio and therefore of outlet temperature deviation during the rundown process.

$$
\begin{aligned}
& (\hat{P / F})=1+A / B \\
& \delta \hat{T}_{0} \equiv \Delta T_{C}[(\hat{P} / F)-1]=\Delta T_{C} A / B
\end{aligned}
$$

By setting $\delta \hat{T}_{0} \leqslant \delta T_{\text {sat }}$, the coolant boiling limit, a nonboiling criterion upon the feedback coefficients is obtained 


$$
\frac{A}{B} \equiv \frac{\left|P_{0} C_{0}\right|-F_{0} \cdot C_{0}}{F_{0} C_{0}} \leqslant \frac{\delta T_{\text {sat }}}{\Delta T_{C}}
$$

where F.C. E flow coefficient.

During flow rundown, positive reactivity generated by decreasing power is compensated by negative reactivity from an increasing power-to-flow ratio. Later on, power continues to decrease primarily because of an increasing inlet temperature and the power-to-flow ratio decreases. As in LOHS, the long-term limit on $\delta T_{j}$ then can be deduced directly from Eq. (1) by letting power go to zero at finite flow with the result

$$
\delta \hat{T}_{i}-\frac{A+B}{\alpha_{i}}
$$

By setting $\delta \hat{T}_{j} \leqslant \delta T_{c \ell}$, a high temperature creep 1 imit for core-support structures, a creep limit criterion upon feedback coefficient is obtained

$$
\frac{A+B}{\alpha_{i}} \equiv \frac{P_{\cdot} C_{0}}{I_{\cdot} C_{0}} \leqslant \delta T_{C l}
$$

For LOF, Eq. (3) reduces to

$$
A[1-P(t)]-B^{\prime}[P(t) / F(t)-1]-\frac{\alpha_{i}}{C_{T}} \int_{0}^{t} d t^{\prime}\left[P\left(t^{\prime}\right)-P_{r}\right]=0
$$

In LOF, flow initially is dominated by pump inertial rundown characteristics -later on it stabilizes under the influence of natural convection (or low level pony-motor flow if the system is so designed). Appendix $C$ shows that in the first regime flow may be approximated by

$$
F(t)=\frac{1}{1+t / \tau}
$$

where $\tau$ is a characteristic time constant. Also, the relationship between natural convection flow and reactor power is developed. This may be used to estimate the time at which natural convection comes to dominate the total 
flow. In natural convection, flow will continue to drift down as power continues to decline. The dependence however is weak -- flow goes roughly as the cube root of power. As an expedient to maintaining simple solutions (linearity) in Eq. (3-b) we neglect this further flow decay and use a fixed flow in the natural convection regime. With pony-motor operation, the flow in fact can be maintained constant. With these two prescribed flow regimes separated at a time $t_{1}, E q .(3-b)$ can be solved with the result;

$$
\begin{aligned}
P(t) & =\left(1-P_{r}^{\prime}\right)\left(1+\frac{B^{\prime}}{A+B^{\prime}} t / \tau\right)-\left(1+\frac{\alpha_{j}^{\tau}}{B^{\top} C_{T}}\right)+P_{r}^{\prime} ; t \leqslant t_{1} \\
& =\left(P_{1}-P_{r}\right) e^{-\alpha}{ }_{i}^{\prime}\left(t-t_{1}\right)+P_{r} ; t \geqslant t_{1}
\end{aligned}
$$

where:

$$
\begin{aligned}
& P_{r}^{\prime}=\frac{P_{r}}{1+\frac{C_{T}{ }^{T}}{\alpha_{i} \tau}} \\
& P_{1}=P\left(t_{1}\right) \\
& \alpha_{i}^{\prime}=\frac{\alpha_{i}}{C_{T}} \frac{1}{A+B^{\top} / F\left(t_{1}\right)}
\end{aligned}
$$

Equation (9) then may be used to track power and temperature through the transient until the power reduces to decay power levels.

\subsection{Overpower Transients}

We define overpower transients (TOP) as reactivity insertion - typically taken to result from withdrawal of a control rod -- plus failure to scram. Primary flow and the entire balance of plant are presumed to continue to operate normally. Under these circumstances, Eq. (3) reduces to 
$-\left[A+B^{\prime}\right][P(t)-1]-\frac{\alpha_{i}}{C_{T}} \int_{0}^{t} d t^{\prime}\left[P\left(t^{\prime}\right)-1\right]+R t=0$

the solution of which is

$$
P(t)-1=\frac{C_{T}}{\alpha_{i}} R\left(1-e^{-t / \tau}\right)
$$

where $\tau \equiv \frac{C_{T}}{\alpha_{i}}\left(A+B^{\prime}\right)$.

For many circumstances of interest, $t / \tau \ll 1$ and $E q$. (15) may be approximated to

$$
P(t)-1=\frac{R t}{A+B^{\prime}}
$$

which in fact is the exact solution for $\alpha_{i}=0$.

\subsection{Explicit Neutron Kinetics}

The equilibrium condition of net reactivity equal to zero at all times can be relaxed while retaining simple solutions which yield some quick insight into further aspects of the transients. The general approach is: (1) to use the one-group prompt jump approximation relating power and reactivity

$$
\frac{d}{d t} p=\lambda \rho p *
$$

where $P$ is power, $\lambda$ is a one-group delayed neutron precursor decay constant, and $\rho$ is reactivity; (2) to use power solutions $P_{0}$ obtained with $\rho=0$ to define a fractional power deviation, $\delta$ as

$$
\frac{p}{P_{0}} \equiv 1+\delta
$$

and (3) to examine solutions in the neighborhood of equilibrium where $\delta \ll 1$ such that Eq. (11) can be linearized. 
The identity,

$$
\frac{d}{d t} P \equiv P_{0} \frac{d}{d t}\left(\frac{P}{P_{0}}\right)+\left(\frac{P}{P_{0}}\right) \frac{d}{d t} P_{0}
$$

can be used in Eq. (1) to get

$$
\frac{d}{d t}\left(\frac{P}{P_{0}}\right)+\left(\frac{1}{P_{0}} \frac{d}{d t} P_{0}\right)\left(\frac{P}{P_{0}}\right)=\lambda \rho\left(\frac{P}{P_{0}}\right)
$$

By expressing $\rho$ as a function of $P / P_{0}$ this equation then is written with $P / P_{0}$ or equivalently, $\delta$, as the dependent variable and can be linearized.

We illustrate this procedure for the specific case of LOF with $\delta T_{j}=0$. In that case:

$$
\text { and, } \begin{aligned}
P_{0} & =\frac{A+B}{A+B / F} \\
& =(A+B)-(A+B / F) P_{0}\left(\frac{P}{P_{0}}\right) \\
& =(A+B)\left(1-\frac{P}{P_{0}}\right)
\end{aligned}
$$

as a specific form for $F$ we write

$$
F(t)=\frac{1}{1+t / \tau}
$$

where $\tau$ is a characteristic time constant. The derivation of Eq. (16) is outlined in Appendix C. It approximates an inertial pump rundown. Equations (12), (14), (15) and (16) then may be used to convert Eq. (11-a) to

$$
\frac{d}{d t}(1+\delta)-\frac{B}{\tau} \frac{1}{A+B(1+t / \tau)}(1+\delta)=-\lambda(A+B) \delta(1+\delta)
$$

and 1 inearized by neglecting $\delta$ compared to 1 in the second and third terms to get 


$$
\frac{d}{d t} \delta+\lambda(A+B) \delta=\frac{B}{\tau} \frac{1}{A+B(1+t / \tau)} .
$$

A linear transformation on the time variable,

$$
\phi \equiv \lambda \tau(A+B)(1+A / B+t / \tau)
$$

converts $\mathrm{Eq} .(11-\mathrm{b})$ to

$$
\frac{\mathrm{d}}{\mathrm{d} \phi} \delta+\delta=\frac{1}{\phi}
$$

the solution of which is

$$
\delta(\phi)=e^{-\phi}\left[E_{i}(\phi)-E_{j}\left(\phi_{0}\right)\right]
$$

where $E_{i}$ is the exponential integral function

$$
E_{i}(\phi) \equiv \int_{-\infty}^{\phi} d x \frac{e^{x}}{x}
$$

and $\phi_{0} \equiv \phi(t=0)$.

The power derivation from neutronic equilibrium, $\delta(\phi)$, is illustrated in Fig. 3. As can be seen, when

$$
\phi_{0} \equiv \lambda \tau \frac{(A+B)^{2}}{B} \geq 2
$$

the deviation is reasonably small.

\section{ACKNOWLEDGMENTS}

I wish to acknowledge many useful discussions with Drs. Edgar E. Morris and Shang F. Su during the development of this work; and Barbara J. Heineman who typed the manuscript. 


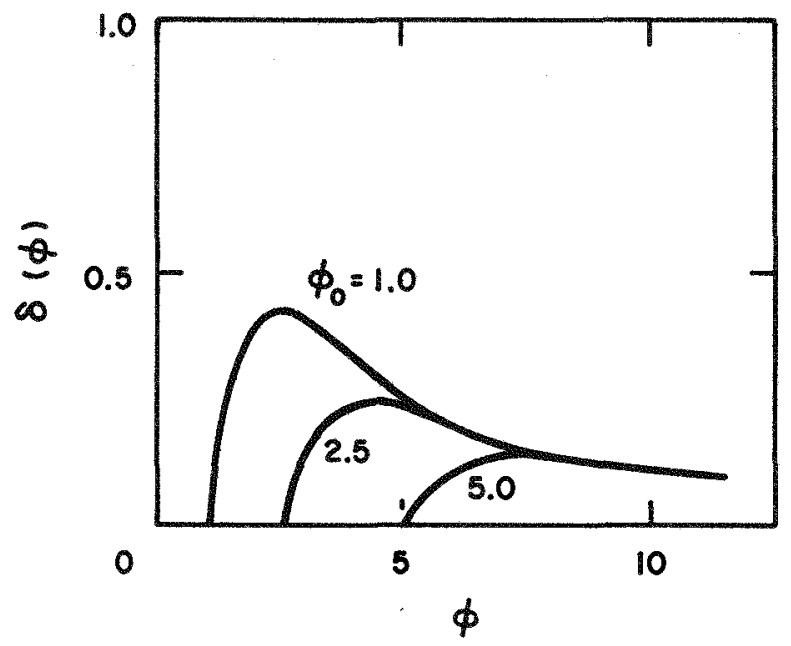

Figure 3. Power Deviation

from Equilibrium 
APPENDIX A

A "POINT" CORE MODEL

The error introduced by computing reactivity feedback from products of spatially averaged temperature distributions and spatially averaged reactivity worth distributions is investigated and found to be small for those transients which may be represented by a quasi-static approximation.

We consider axial distributions only and write reactivity as:

$$
\begin{aligned}
\frac{d \rho}{d \theta} & =\sum_{j} \alpha_{j}(\theta) \delta T_{j}(\theta) \\
& =\frac{\alpha_{j}}{2 \hat{\theta} C_{j}} \int_{0}^{t} d t^{\prime}\left[P\left(t^{\prime}\right)-P_{r}\left(t^{\prime}\right)\right] \\
& +\alpha_{c}(\theta) \frac{\Delta T_{C}}{2}\left[\frac{P(t)}{F(t)}-1\right]\left(1+\frac{\sin \theta}{\sin \hat{\theta}}\right) \\
& +\alpha_{f}(\theta) \frac{\Delta T_{f}}{2}[P(t)-1] \cos \theta
\end{aligned}
$$

where:

(1) The $\alpha$ 's are temperature coefficients (reactivity per unit temperature); subscripts, $i=$ coolant inlet temperature, $f=$ fuel temperature, and $c=$ coolant temperature increase across the core.

(2) The $\delta T$ 's are deviations in temperature from normal steady state; subscripts as above.

(3) $P(t)=$ relative power as a function of time.

(4) $P_{r}(t)=$ primary system heat rejection rate.

(5) $F(t)=$ relative flow. 
(6) $C_{i}=$ inlet plenum heat capacity.

(7) $\Delta T^{\prime} s=$ normal steady-state temperature rise across: coolant channel, sub $c$; and fuel rod, sub $f$.

(8) $\theta=\frac{\pi}{2} \frac{Z}{H / 2+\delta} ; Z=$ axial location measured from zero at the axial midplane, $H=$ core height, $\delta=$ reflector savings. $\delta=\pi / 4$ for a wide variety of core designs which leads to a maximum angle, $\hat{\theta}=\pi / 3$.

(9) A "chopped" cosine axial power distribution is assumed.

(10) $\rho$ = reactivity.

Equation (A-1) follows directly from a quasi-static approximation which assumes that the various temperature distributions may be represented by the steady-state distributions corresponding to the instantaneous power and flow.

We assume worth distributions, $\alpha_{j}(\theta)$, symmetric about $\theta=0$ such that $\alpha_{j}(-\theta)=\alpha_{j}(\theta)$.

We compare the exact feedback,

$$
\rho=\sum_{j} \int_{-\hat{\theta}}^{\hat{\theta}} d \theta \alpha_{j}(\theta) \delta T_{j}(\theta)
$$

with

$$
\rho^{\prime}=\sum_{j} \int_{-\hat{\theta}}^{\hat{\theta}} d \theta \alpha_{j}(\theta) \int_{-\hat{\theta}}^{\hat{\theta}} d \theta \frac{\delta T_{j}(\theta)}{2 \hat{\theta}}
$$

These operations yield identical results for the first two terms in Eq. $(A-1)$ : in the first term because $\delta T_{i} \equiv \frac{1}{C_{i}} \int_{0}^{t} d t^{\prime}\left[P\left(t^{\prime}\right)-P_{r}\left(t^{\prime}\right)\right] \neq f(\theta)$; in the 
second term because $\alpha_{c}(\theta)=\alpha_{c}(-\theta)$ is even and $\sin \theta$ is odd. To investigate the third term we use a specific (self adjoint) worth distribution, $\alpha_{f}(\theta)=$ $\cos ^{2} \theta$, with the result

$$
\begin{aligned}
& \frac{\rho(3)}{\frac{\Delta T_{f}}{2}(P-1)}=\frac{2}{3} \sin \hat{\theta}\left(\cos ^{2} \hat{\theta}+2\right)=1.30 \\
& \frac{\rho^{\prime}(3)}{\frac{\Delta T_{f}}{2}(P-1)}=\left(\hat{\theta}+\frac{1}{2} \sin 2 \hat{\theta}\right) \frac{\sin \hat{\theta}}{\hat{\theta}}=1.22
\end{aligned}
$$

Each term therefore is well represented by a product of the averages. The error introduced may be judged smali compared to the uncertainty in the absolute normalization of the $\delta T^{\prime} s$ and $\alpha$ 's. 
APPENDIX B

FEEDBACK COEFFICIENTS

The feedback coefficient in Eq. (1) of the text are defined as:

$$
\begin{aligned}
& A=-\left(\alpha_{d}+\alpha_{e}\right) \frac{\Delta T_{f}}{2} \\
& B=-\left(\alpha_{d}+\alpha_{e}+\alpha_{N a}+2 \alpha_{r}+2 \alpha_{b}\right) \frac{\Delta T_{c}}{2} \\
& \alpha_{i}=-\left(\alpha_{d}+\alpha_{e}+\alpha_{N a}+\alpha_{g}\right)
\end{aligned}
$$

$\Delta T_{f}$ and $\Delta T_{C}$ are temperature rise at full power anu flow across fuel roud radius and coolant channel respectively, $\alpha$ 's are reactivity temperature coefficients with subscripts; $d \equiv$ Doppler, $e$ fuel axial expansion, $\mathrm{Na} \equiv$ sodium expansion, $r \equiv$ control rod drive shaft expansion, $b \equiv$ bowing, and $g \equiv$ grid plate expansion.

Differentiation of Eq. (1) shows that

$-(A+B)=\frac{\partial p}{\partial p} \equiv$ power coefficient

$B=\frac{\partial \rho}{\partial F} \equiv$ flow coefficient

$-\alpha_{i}=\frac{\partial \rho}{\partial \delta T_{i}} \equiv$ inlet temperature coefficient 


\section{APPENDIX C \\ FLOW CHARACTERISTICS}

Loss-of-flow transients are driven by the flow rundown characteristic -flow as a function of time -- of the particular system being considered. An approximate general form for this characteristic can be determined by assuming that the rate of change of the pump rotational kinetic energy equals the rate of frictional energy dissipation around the loop and that the frictional pressure drop is proportional to flow squared. This approximation leads to

$$
F(t)=\frac{1}{1+t / \tau}
$$

where $F(t)$ is the mass flow rate at time $t$ relative to that at time zero and $\tau$ is a characteristic time determined by the specific pump and system design.

Equation $(\mathrm{C}-1)$ neglects a natural convection flow component which will exist in most reactor designs. This component typically will be small ( 1\%) under normal operating conditions but in LOF it eventually comes to dominate the entire residual flow.

For many cases of interest fully turbulent flow will persist throughout the flow rundown and natural convection regimes. In turbulent flow, natural convection flow is related to power as

$$
F_{n}(t)=\left[\frac{g h \bar{p} \beta \Delta T_{C} P(t)}{K}\right]^{4 / 11}
$$

where: $\quad g=$ gravitational acceleration constant

$h=$ vertical separation of core and heat-sink thermal centers

$\bar{\rho}=$ average fluid density

$\beta=$ fluid volumetric thermal expansion coefficient

$\Delta T_{C}=$ coolant temperature rise under normal full power and flow conditions

$K=$ system pressure drop at full flow 


$$
\begin{aligned}
F_{n}(t) & =\text { natural convection flow rate relative to normal full flow } \\
P(t) & =\text { relative power }
\end{aligned}
$$

The equation may be derived by equating the pressure difference due to density difference in the hot and cold legs to the frictional pressure drop as a function of flow. 